\title{
ULTRAFINE PARTICLES AND THEIR POSSIBLE ROLE IN ETIOLOGY AND DEVELOPMENT OF NEURODEGENERATIVE DISEASES
}

\author{
Jan TOPINKA, Táňa ZÁVODNÁ, Andrea RÖSSNEROVÁ, Pavel RÖSSNER, Jr. \\ Institute of Experimental Medicine, Czech Academy of Sciences, Prague, Czech Republic, EU, \\ jan.topinka@iem.cas.cz, tana.zavodna@iem.cas.cz,pavel.rossner@iem.cas.cz
}

https://doi.org/10.37904/nanocon.2019.8658

\begin{abstract}
Air pollutants have been shown to cause a vast amount of different adverse health effects. These effects include impairment of many respiratory (e.g. asthma, chronic obstructive pulmonary disease) and cardiovascular (ischemic heart disease, infarction, stroke) diseases. However, in recent years, the evidence showing effects beyond the lungs and circulatory system are becoming more evident. Neurological diseases, namely Alzheimer's disease (AD) has shown to be associated with living near traffic. However, reason for this has remained unresolved until today. Our new H2020 project TUBE aims on revealing the mechanisms of action of ultrafine particles involved in neurological diseases. The TUBE consortium includes experts in areas of aerosol technology, emission research, engine and fuel research, human clinical studies, epidemiology, emission inventories, inhalation toxicology, neurotoxicology and disease mechanism studies. This enables research of resolving the effects of nanoparticles from different traffic modes for both air quality and concomitant toxic effect of these air pollutants. We will investigate adverse effects of air pollutants using cell cultures, animal exposures and volunteered human exposures as well as the material from epidemiological cohort study. These are going to be compared according to inflammatory, cytotoxic and genotoxic changes and furthermore beyond the current state of the art to neurotoxic and brain health effects. With this approach, we are aiming to a comprehensive understanding of the adverse brain effects of nanoparticles from traffic.
\end{abstract}

Keywords: Alzheimer`s disease, inflammation, neurodegenerative diseases, ultrafine particles

\section{INTRODUCTION}

Air pollution, a massive public health issue known to pose a major threat to human health, is an important, ever-increasing global concern. Every year, 6.5 million premature deaths from cardiovascular and respiratory conditions occur as a direct result of exposure to air pollutants, especially to particulate matter (PM) [1]. A growing body of experimental proof from epidemiological studies and controlled animal studies shows that exposure to air pollutants also impairs the brain [2]. Living in highly polluted areas is associated exacerbated cognitive dysfunction and neurodegenerative diseases such as Alzheimer's disease [3]. As has been shown recently, the association of air pollution to adverse health effects is particularly notable with traffic-related pollutants [4].

Despite decades of Alzheimer's disease (AD) research, the real molecular pathophysiology of the disease is still poorly understood, and treatments remain inadequate. Remarkably little attention is paid to the involvement of environmental factors, which are known from epidemiological studies to strongly impact AD generation [5]. Furthermore, even though the majority of patients suffer from sporadic, or early-onset AD (LOAD), most preclinical research is carried out using genetic models, or studies focus solely on genetic risk factors. The role of nanoparticles which are known by their ability to pass blood-brain barrier in the pathophysiology of neurodegenerative diseases is still poorly understood. This overview shortly summarize the current knowledge in this very actual and quickly developing field. 


\section{NEURODEGENERATION AND NANOPARTICLES - SCIENTIFIC PROBLEMS TO BE SOLVED}

\subsection{Translocation of Inhaled Nanoparticles into the Brain}

There are 3 major pathways of the translocation of NPs into the brain (Figure 1). Olfactory and trigeminal nerves represent neural pathways of the translocation. Systemic pathway via blood circulation means translocation of inhaled NPs into blood (into nasal veins or through alveolae membranes) and the distribution via blood around body. To enter the brain, NPs have to cross the blood-brain barrier. Besides NPs, blood can carry into the brain proinflammatory markers (especially cytokines) that were produced and released into the blood circulation by cells as a consequence of their interactions with NPs (cytokines can cross the blood-brain barrier).

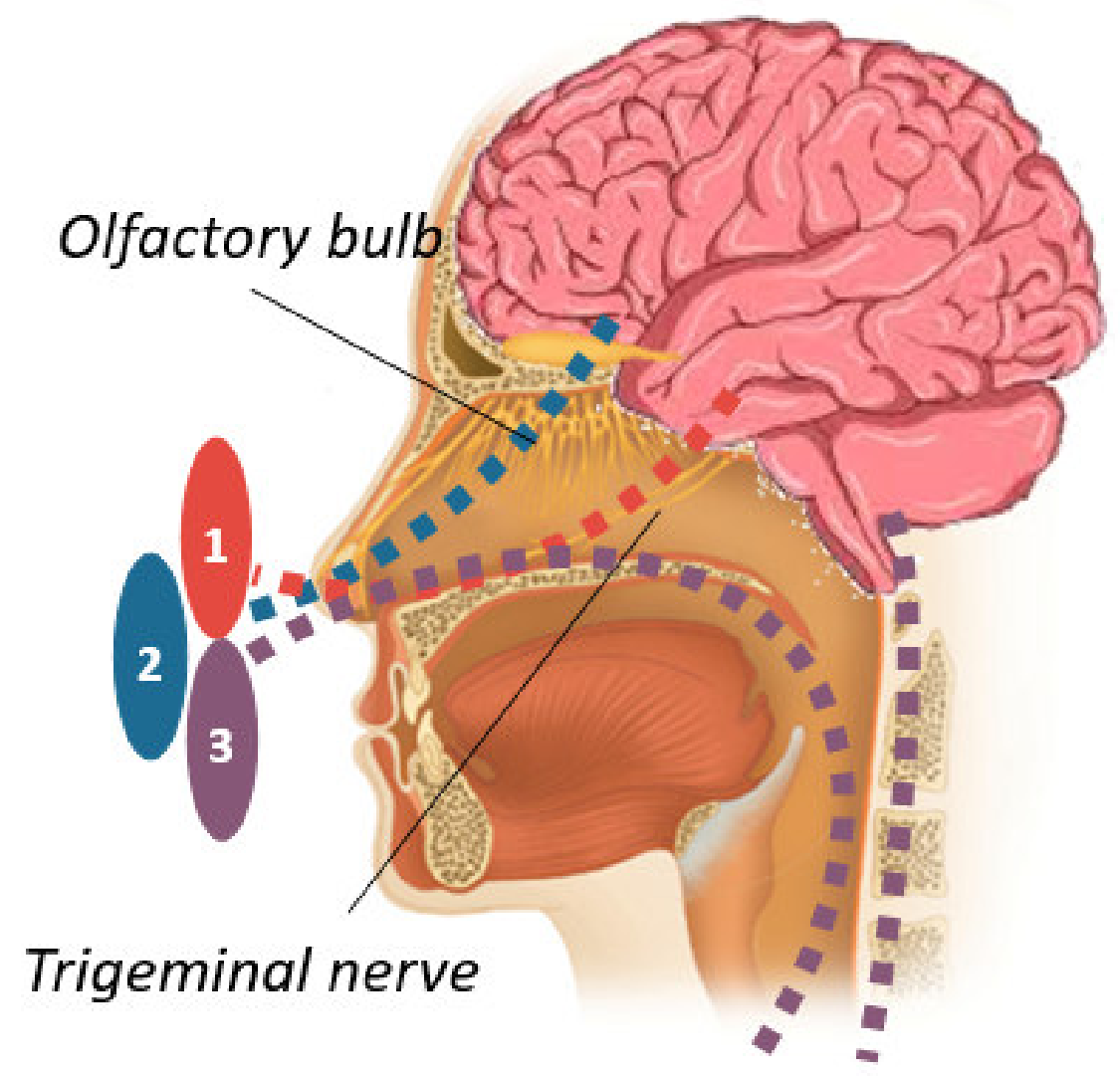

Figure 1 Pathways of the translocation of NPs into the brain: 1. Olfactory nerve, 2. Trigeminal nerve,

3. Systemic pathway via blood circulation

The kinetics of the NPs translocation varies between minutes (for the translocation along nerves) and hours and days (through nerve axons). The same routes are used in (nano) medicine.

\subsection{Neurodegenerative diseases potentially associated with exposure to nanoparticles}

Common symptoms of all neurodegenerative diseases are cognitive function decline (dementia) and motion problems (ataxia) [6]. Different location of the brain damage and different macroscopic and microscopic manifestations of various neurodegenerative diseases are shown in Figure 2. On the macroscopic level, atrophy of the affected section of the brain occurs. On the microscopic level, deposition and accumulation of defective proteins occurs. 


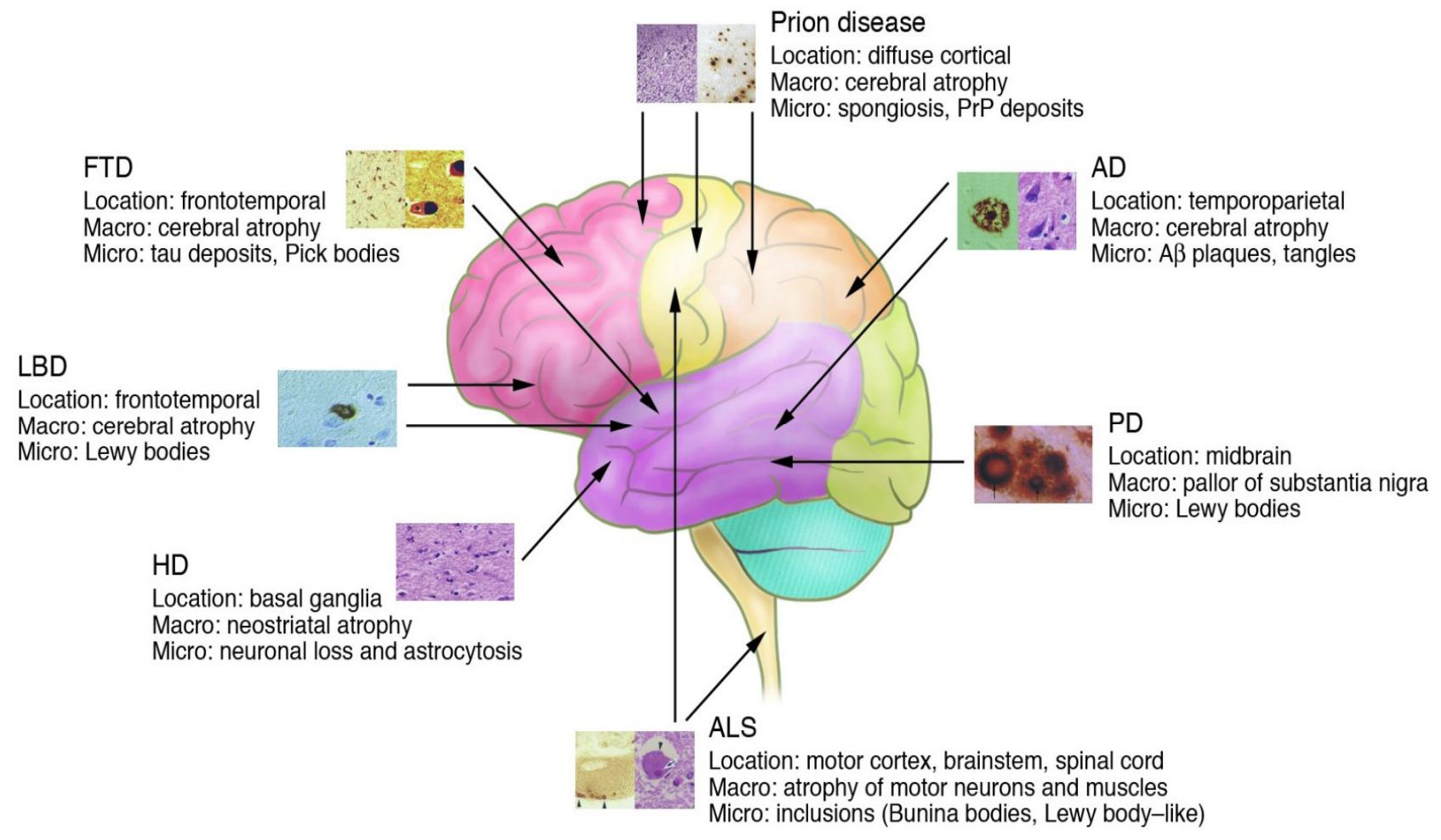

Figure 2 Localisation and symptoms of various neurodegenerative diseases in human brain

(AD - Alzheimer`s disease; PD - Parkinson`s disease; ALS - Amyotrophic lateral sclerosis; HD - Huntington`s disease; LBD - Lewy bodies dementia; FTD - Frontotemporal dementia. According to [18]

\subsection{Major Causes of Neurodegeneration}

Causes of neurodegeneration are multifactorial with prevailing genetic predisposition. However, it is generally accepted that environmental factors significantly contribute to the disease development. Major factors are toxic metal exposure (e.g. As, $\mathrm{Pb}, \mathrm{Mn}$ ), exposure to pesticides, fungicides, insecticides, exposure to polychlorinated biphenyls, polybrominated biphenyls (flame retardants), other industrial chemicals and bacterial toxins (endotoxins) as well as lifestyle factors (diet, smoking) [7]. Polluted environment, especially air pollution by particulate matter (including combustion generated ultrafine particles and engineered nanoparticles air) might be also significant contributing factor.

\subsection{Mechanisms of Nanoparticle Neurotoxicity}

Main mechanisms of nanoparticle neurotoxicity are shown in Figure 3. Main mechanism is oxidative stress causing damage to macromolecules and cell damage by reactive oxygen species in neurons and glial cells. Oxidative stress may induce apoptosis and/or autophagy leading to microglia and astrocyte activation. Further effects include mitochondrial dysfunction, redox imbalance, lipid peroxidation, protein oxidation, DNA damage and signal transduction interference [8].

Direct action of NPs and formation of ROS leads to neuro-inflammation connected with the release of the inflammatory cytokines, impairment of neurotransmitter release, neuron loss, altered neuronal connectivity blood brain barrier lesions, changes in transporter proteins and aggregation of beta-amyloid and other proteins playing the crucial role in $A D$ aetiology. 


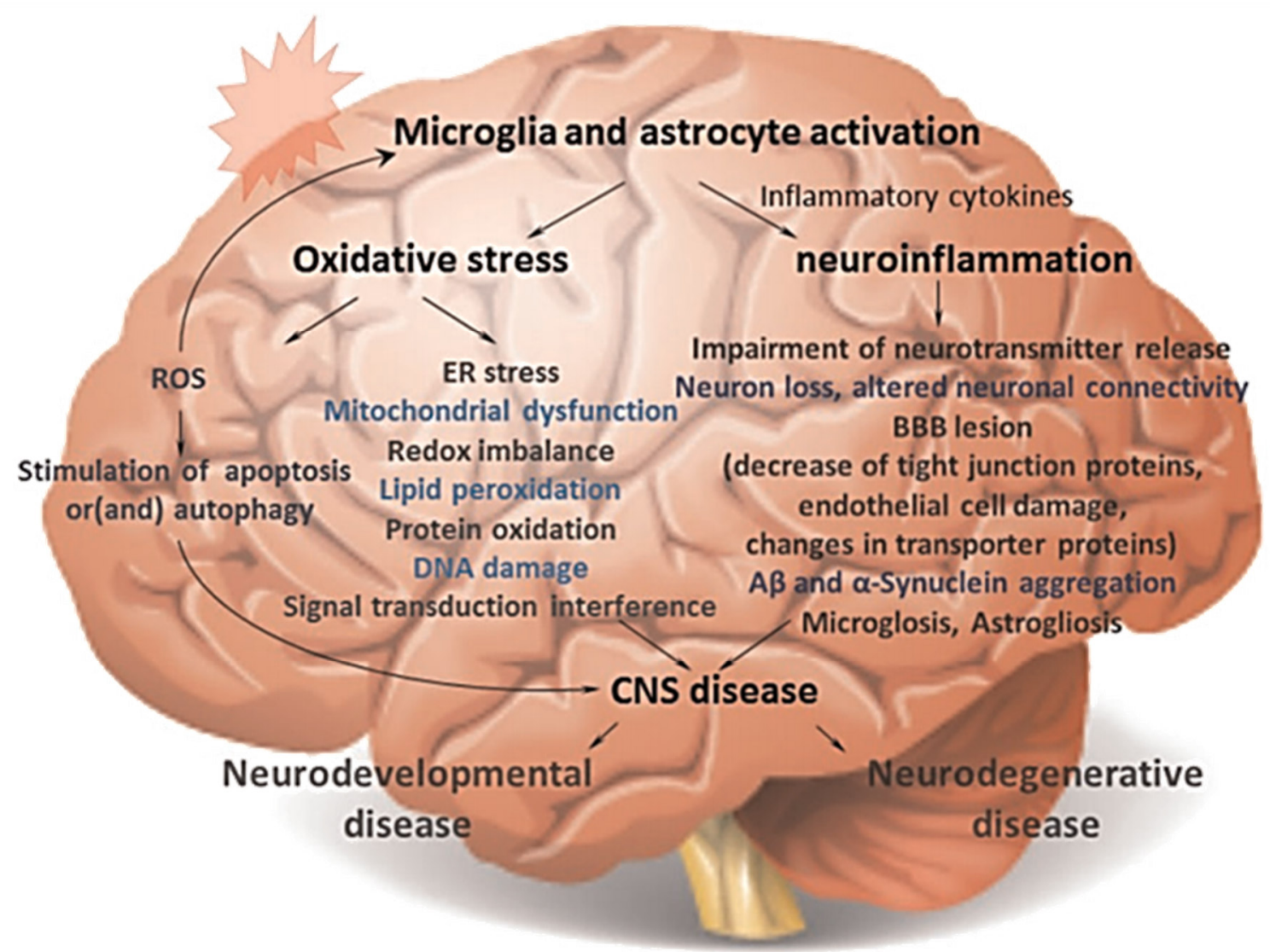

Figure 3 Mechanisms of Nanoparticle Neurotoxicity According to [22]

\subsection{Alzheimer's disease}

$A D$ is the most common neurodegenerative disease and the most common cause of dementia (over $60 \%$ of all dementia cases are caused by $A D$ ). $A D$ is incurable, treatment with cognitive enhancers can mitigate, however not reverse, the disease progression). Cognitive and behavioural symptoms of AD include memory loss affecting ability to complete normal daily tasks, difficulties in performing familiar activities, speech difficulties, time and spatial disorientation, impaired ability to make rational judgement, difficulties with abstract thinking, changes in mood or behaviour, personality changes and loss of initiative.

Probability of the development, of the disease increases with age. In the Czech Republic, it was estimated that $20 \%$ of people older than 80 years and $50 \%$ of people older than 90 years are affected by AD [9]. More than 106 mil., people worldwide will suffer by AD in the year of 2050 [10].

There are several studies suggesting that smog episodes exacerbate symptoms of neurological diseases [11]. It was found that young adults from areas with heavy air pollution exhibited higher AD biomarker levels in their cerebrospinal fluid and had higher risk of $A D$ development later in life [12]. Also, a higher inflammation level and oxidative stress were detected in brains of experimental animals exposed to polluted air [13].

\section{CONCLUSIONS}

Recent development of molecular biology and toxicology opened new possibilities in discovery new biomarkers of $A D$ and other neurodegenerative diseases in populations exposed to combustion generated and engineered nanoparticles. Particularly "omics" technologies should enable to identify all crucial genetic and epigenetic 
changes leading to the development of $A D$. These findings may lead to new methods of prevention and treatment of $A D$.

\section{ACKNOWLEDGEMENTS}

\section{Supported by Ministry of Education, Youth and Sports, Research Infrastructure NanoEnviCz, Grant No. LM2015073 and Grant No. LO1508.}

\section{REFERENCES}

[1] POWER, Melinda C., ADAR, Sara D., YANOSKY, Jeff D. and WEUVE, Jennifer. Exposure to air pollution as a potential contributor to cognitive function, cognitive decline, brain imaging, and dementia: a systematic review of epidemiologic research. Neurotoxicology. 2016. vol. 56, pp. 235-253.

[2] WAINAINA, Moses N., CHEN, Zhichun and ZHONG, Chunjiu. Environmental factors in the development and progression of late-onset Alzheimer's disease. Neuroscience bulletin. 2014. vol. 30, no. 2, pp. 253-270.

[3] LIM, Stephen S., VOS, Theo, FLAXMAN, Abraham D., DANAEI, Goodarz, SHIBUYA, Kenji, ADAIR-ROHANI, Heather ALMAZROA, Mohammad A. et al. A comparative risk assessment of burden of disease and injury attributable to 67 risk factors and risk factor clusters in 21 regions, 1990-2010: a systematic analysis for the Global Burden of Disease Study 2010. The Lancet. 2012. vol. 380, no. 9859, pp. 2224-2260.

[4] HEUSINKVELD, Harm J., WAHLE, Tina, CAMPBELL, Arezoo, WESTERINK, Remco H.S., TRAN, Lang, JOHNSTON, Helinor, STONE, Vicki, CASSEE, Flemming R. and SCHINS, Roel P.F. Neurodegenerative and neurological disorders by small inhaled particles. Neurotoxicology. 2016. vol. 56, pp. 94-106.

[5] BLOCK, Michelle L. and CALDERÓN-GARCIDUEÑAS, Lilian. Air pollution: mechanisms of neuroinflammation and CNS disease. Trends in neurosciences. 2009. vol. 32, no. 9, pp. 506-516.

[6] BERTRAM, Lars, and TANZI, Rudolph E. The genetic epidemiology of neurodegenerative disease. The Journal of clinical investigation. 2005. vol. 115, no. 6, pp.1449-1457.

[7] SHEIKH, Saba, EJAZUL, Haque, and SNOBER, S. Mir. Neurodegenerative diseases: multifactorial conformational diseases and their therapeutic interventions. Journal of neurodegenerative diseases. 2013, https://doi.org/10.1155/2013/563481.

[8] WANG, Yan, Lilin Xiong, and TANG, Meng. Toxicity of inhaled particulate matter on the central nervous system: neuroinflammation, neuropsychological effects and neurodegenerative disease. Journal of Applied Toxicology. 2017. vol. 37, no. 6, pp. 644-667.

[9] MÁTL, Ondřej, MÁTLOVÁ, Martina and HOLMEROVÁ, Iva. Zpráva o stavu demence 2016 Kolik zaplatíte za péči? Česká alzheimerovská společnost, o.p.s. ISBN 978-80-86541-50-1.

[10] BROOKMEYER, Ron, JOHNSON, Elizabeth, ZIEGLER-GRAHAM, Kathryn, and ARRIGHI, H. Michael. Forecasting the global burden of Alzheimer's disease. Alzheimer's \& dementia. 2007. vol. 3, no. 3, pp. 186-191.

[11] CUI, Liangliang, CONWAY, George A., JIN, Lan, ZHOU, Jingwen, ZHANG, Jun, LI, Xinwei, ZHOU, Lei, LI, Tiantian and ZHANG, Ji. Increase in medical emergency calls and calls for central nervous system symptoms during a severe air pollution event, January 2013, Jinan City, China. Epidemiology. 2017. vol. 28, pp. S67-S73.

[12] CALDERÓN-GARCIDUEÑAS, Lilian, AVILA-RAMíREZ, José, CALDERON-GARCIDUENAS, Ana, GONZÁLEZHEREDIA, Tonatiuh, ACUÑA-AYALA, Hilda, CHAO, Chih-kai, THOMPSON, Charles, RUIZ-RAMOS, Rubén, CORTÉS-GONZÁLEZ, Victore, MARTíNEZ-MARTÍNEZ, Luze, GARCÍA-PÉREZ, Mario A., REIS, Jacquesg, MUKHERJEE, Partha S., TORRES-JARDÓN, Ricardoi and LACHMANN, Ingolfj. Cerebrospinal fluid biomarkers in highly exposed PM 2.5 urbanites: The risk of Alzheimer's and Parkinson's diseases in young Mexico City residents. Journal of Alzheimer's Disease. 2016. vol. 54, no. 2, pp. 597-613.

[13] CALDERÓN-GARCIDUEÑAS, Lilian, HEYDARPOUR, Leray, POURIA, Emmanuelle, TORRES-JARDÓN, Ricardo and REIS, Jacques. Air pollution, a rising environmental risk factor for cognition, neuroinflammation and neurodegeneration: the clinical impact on children and beyond. Revue neurologique. 2016. vol. 172, no. 1, pp. 6980. 